\title{
Separation of cis/trans fatty acid isomers on gas chromatography compared to the Ag-TLC method
}

\author{
By C. Ravi Kiran, M.V. Reshma* and A. Sundaresan \\ National Institute for Interdisciplinary Science and Technology (formerly RRL), \\ Council of Scientific and Industrial Research, Trivandrum, India \\ * Corresponding author: reshmamv2001@yahoo.co.in
}

\section{RESUMEN}

Separación de isómeros cis/trans de ácidos grasos mediante cromatografía de gases, comparación con el método Ag-TLC.

El presente estudio investiga la separación de isómeros cis/trans de ácidos grasos mediante cromatografía de gases (GC) utilizando una columna de SP2560 de $75 \mathrm{~m}$ y diferentes condiciones que incluyen un programa isotérmico y una programación temperatura-tiempo. La programación temperatura-tiempo mostró una mejor separación de isómeros cis $/$ trans de los ácidos grasos $\mathrm{C}_{14 \cdot 1}, \mathrm{C}_{16 \cdot 1}, \mathrm{C}_{18 \cdot 1 \cdot}, \mathrm{C}_{18 \cdot 2}$ y $\mathrm{C}_{18: 3}$ con los ácidos grasos de cadena corta en comparación con el programa isotermo. La separación de los isómeros trans/trans de los ácidos grasos $C_{18: 1}$ incluyendo ácido elaídico $\left(C_{18: 1} \Delta 9 t\right)$ y ácido vaccénico $\left(C_{18: 1} \Delta 11 \mathrm{t}\right)$ fué difícil mediante programación temperatura-tiempo. La cromatografía en capa fina impregnada con nitrato de plata (Ag-TLC) se realizó para separar fracciones cis/trans y el análisis de la fracciones se llevó a cabo mediante GC. El análisis GC mostró co-elución de los isómeros trans del ácido graso $\mathrm{C}_{18.1}$. Así, el estudio muestra que una programación temperatura-tiempo en GC con columna de cianopropilo altamente polar es suficiente para resolver los ácidos grasos trans, junto con los ácidos grasos de cadena corta cuando un gran número de muestras tiene que ser analizado.

PALABRAS CLAVE: Ácidos grasos trans - Cromatografía de gases - Fraccionamiento Ag-TLC - Resolución

\section{SUMMARY}

Separation of cis/trans fatty acids isomers on gas chromatography compared to the Ag-TLC method

The present study investigates the separation of the cis/ trans isomers of fatty acids on the $75 \mathrm{~m}$ SP2560 column under different gas chromatographic (GC) conditions including an isothermal program and a time-temperature program. The time-temperature program showed improved separation of cis/trans isomers of $\mathrm{C}_{14: 1}, \mathrm{C}_{16: 1}, \mathrm{C}_{18: 1}, \mathrm{C}_{18: 2}$ and $\mathrm{C}_{18: 3}$ fatty acids along with short chain fatty acids compared to the isothermal program. The separation of trans/trans isomers of $\mathrm{C}_{18: 1}$ fatty acids including elaidic acid $\left(\mathrm{C}_{18: 1} \Delta 9 \mathrm{t}\right)$ and vaccenic acid $\left(\mathrm{C}_{18: 1}\right.$ $\Delta 11 \mathrm{t})$ was difficult with the time-temperature program. The thin layer chromatography impregnated with silver nitrate (AgTLC) method was performed to separate cis/trans fractions and GC analysis was carried out with the trans fraction. But GC analysis showed a co-elution of trans isomers of $C_{18: 1}$ fatty acid. Thus the study shows that a time-temperature programmed GC method with the highly polar cyanopropyl column is sufficient to resolve trans fatty acids along with short chain fatty acids when a large number of samples has to be analyzed.

KEY WORDS: Ag-TLC fractionation - Gas chromatography - Resolution - Trans fatty acids.

\section{INTRODUCTION}

Trans fat comprises unsaturated fatty acids having one or more isolated double bonds in the trans geometric configuration (U.S.FDA, 2003). Trans fatty acids (TFA) in food originate from three major sources, 1) through partial hydrogenation of fats, 2) high-temperature processing of edible oils, 3) from the natural occurrence of TFA in ruminant meat and dairy products (Valenzuela et al., 1995; Mjøs, 2005; Tsuzuki et al., 2010). Due to the presence of TFA, partially hydrogenated oils have some commercial advantages over many non-hydrogenated oils, such as longer shelf life, solidity at room temperature and greater stability during high temperature commercial deep frying (Micha and Mozaffarian, 2008). Several epidemiological and clinical studies on the health effects of TFA published in the last few years indicate that TFA intake may be a risk factor for cardiovascular disease (Mozaffarian et al., 2006; Valenzuela et al., 2011). Analysis of trans isomers of fatty acids has taken on more importance, since the world health organization recommended that the intake of trans fat should be limited to $<1 \%$ of the overall energy intake (Fournier et al., 2007). In 2003, the U.S. food and drug administration (FDA) also passed a labeling requirement for trans fat in packaged food products, effective January 1, 2006, requiring it to be reported on the nutrition label if present at $\geq 0.5 \mathrm{~g} /$ serving, but allowed for it to be declared zero if the product contained $<0.5 \mathrm{~g} /$ serving. In the context of food labeling and nutrition trans fat does not include fatty acids with conjugated trans double bonds. Several analytical methods are reported for the determination and quantification of TFA in food samples including gas chromatography (GC), gas chromatography-mass spectrometry (GC-MS), thin layer chromatography impregnated with silver nitrate (Ag-TLC), liquid chromatography impregnated with silver nitrate (Ag-LC) and Fourier 
transformed infrared spectroscopy (FT-IR). Each of these methods exhibits advantages and drawbacks. GC can be accomplished with equipment available in many laboratories; it detects lower levels of TFA and allows for the quantification of individual fatty acids in the course of determining a full fatty acid profile (Phillips et al., 2010; Juanéda et al., 2007; Molkentin and Precht, 1995; Ratnayake and BeareRogers, 1990; Ledoux et al., 2000; Huang et al., 2006; Aro et al., 1998; Delmonte and Rader, 2007; Tasan et al., 2011).

Ratnayake et al., (2002) discussed the temperature sensitive resolution of cis/trans isomers of fatty acid isomers in PHF on $100 \mathrm{~m}$ SP2560 and CP-Sil88 capillary columns on GC, which eventually lead to the approval of AOCS Ce 1h-05 method for determination of cis/trans fatty acids vegetable or non-ruminant fats and oils (Ratnayake et al., 2006). An analysis of ruminant fats including butter with shorter chain fatty acids cannot be separated by this method. Moreover, a single method cannot be applied to the same type of column with different lengths. In this context, the present study discusses the variations in resolution between cis/trans isomers of major fatty acids along with short chain fatty acids at different chromatographic conditions on the $75 \mathrm{~m}$ SP 2560 column. We have also compared the GC method with Ag-TLC coupled with the GC method and highlighted its advantages and disadvantages.

\section{MATERIALS AND METHODS}

\subsection{Reagents and standards}

Standards of fatty acids methyl esters (FAME) $\left(\mathrm{C}_{4: 0}\right.$ Methyl butyrate, $\mathrm{C}_{6: 0}$ Methyl caproate, $\mathrm{C}_{8: 0}$ Methyl capryllate, $\mathrm{C}_{10: 0}$ Methyl caprate, $\mathrm{C}_{12: 0}$ Methyl laurate, $C_{14: 0}$ Methyl myristate, $C_{14: 1}-9 \mathrm{c}$ Methyl myristoleate, $C_{14: 1}-9$ t Methyl myristelaidate, $C_{16: 0}$ Methyl palmitate, $\mathrm{C}_{16: 1}-11 \mathrm{C}$ Methyl palmitoleate, $\mathrm{C}_{16: 1}-11 \mathrm{t}$ Methyl palmitelaidate, $\mathrm{C}_{18: 0}$ Methyl stearate, $C_{18: 1}-9 \mathrm{c}$ Methyl oleate, $C_{18: 1}-9 \mathrm{t}$ Methyl elaidate, $C_{18: 1}-11 t$ Methyl vaccenate, $C_{18 \cdot 2}-9 c, 12 c$ linoleate (cis/trans isomer mixture), $\mathrm{C}_{18: 2}-9 \mathrm{c}, 11 \mathrm{c}$ \& 10c, 12c linoleate (CLA cis/trans isomer mixture), $\mathrm{C}_{18: 3}-9 \mathrm{c}, 12 \mathrm{c}, 15 \mathrm{c}$ Methyl linolenate (cis/trans isomer mixture), $\mathrm{C}_{20: 0}$ Methyl arachidate, $\mathrm{C}_{20: 5}$ Methyl eicosapentaenoate, $\mathrm{C}_{22: 6}$ Methyl docosahexanoate), Supelco 37 component FAME standard mixture were purchased from Sigma (Steinheim, Germany). Silver nitrate $\left(\mathrm{AgNO}_{3}\right)$, Silica Gel 'G' for Thin layer chromatography (TLC) with particle size 10-40 microns and TLC Aluminum sheets $(20 \times 20 \mathrm{~cm})$ with silica gel $60 \mathrm{~F}_{254}$ and High Performance Liquid Chromatography (HPLC) grade solvents were purchased from Merck (Darmstadt, Germany).

\subsection{Samples for study}

For the present study partially hydrogenated fat (PHF), butter, puff and cake samples were collected from local market and subjected to further analysis.

\subsection{ANALYTICAL METHODS}

\subsubsection{Sample preparation}

Fat extraction was carried out according to the Folch extraction method (Folch et al., 1957). This method was selected as the reference for fat extraction because of its mild working conditions, which avoid potential alterations of the extracted fat (Ruiz-Jiménez et al., 2004). Fatty acid methyl esters (FAME) were prepared by esterifying them with alcoholic sulfuric acid reagent according to the International Union of Pure and Applied Chemistry (IUPAC) procedure (IUPAC, 1987).

\subsubsection{GC analysis}

The FAME was analyzed using a Shimadzu GC 2010 fitted with a split injector $\left(250^{\circ} \mathrm{C}\right)$ and a flame ionization detector (FID $300^{\circ} \mathrm{C}$ ). A highly polar cyanopropyl capillary column, SP-2560 (Supelco column $75 \mathrm{~m}, 0.18 \mathrm{~mm}$ i.d. with 0.14 $\mu \mathrm{m}$ film thickness) was used and operated at a) isothermal program at $180^{\circ} \mathrm{C}, \mathrm{b}$ ) time-temperature program which included an $80^{\circ} \mathrm{C}$ hold for $2 \mathrm{~min}$ to $200^{\circ} \mathrm{C}$ with a $10{ }^{\circ} \mathrm{C} \mathrm{min}^{-1}$ raise, hold for $30 \mathrm{~min}$. followed by a further increase to $220^{\circ} \mathrm{C}$ with a

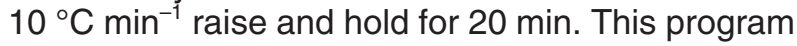
was selected after checking the resolution between different cis/trans fatty acids at different timetemperature ramping modes. Nitrogen was used as carrier gas at a linear velocity of $13.0 \mathrm{~cm} \mathrm{~s}^{-1}$. Another experiment was performed using helium as carrier gas to check the effect of the carrier gas on the resolution between fatty acids at the same timetemperature program mentioned above at a linear velocity of $13.0 \mathrm{~cm} \mathrm{~s}^{-1}$ and also at $17.0 \mathrm{~cm} \mathrm{~s}^{-1}$. FAME were identified by comparing their retention time with authentic standards, and the peaks were quantified using digital integration according to the AOCS official method Ce 1-62 (AOCS, 2003). The fatty acid levels were reported as the relative proportions of the total composition.

\subsubsection{Resolution}

Resolution $\left(R_{s}\right)$ is the measurement of separation between two eluted peaks. Resolution is the most important parameter to optimize a chromatographic method. The resolution, $R_{s}$, between two peaks in a chromatogram is usually calculated by,

$$
R_{s}=2\left(t_{R(2)}-t_{R(1)}\right) /\left(w_{h(1)}+w_{h(2)}\right)
$$

Where $t_{R(1)}$ and $t_{R(2)}$ are the retention times of the two peaks and $\mathrm{w}_{\mathrm{h}(1)}$ and $\mathrm{w}_{\mathrm{h}(2)}$ are the corresponding peak widths at half peak height (Ettre, 1993).

\subsection{4. $L O D$ and $L O Q$}

Limit of detection (LOD) and limit of quantification $(\mathrm{LOQ})$ are important factors in the optimization in 
any chromatographic analysis, which depends on instrumental sensitivity. LOD and LOQ for TFA analysis in this study were calculated by signal to the noise ratio of individual FAME components (Ettre, 1993).

\subsubsection{Separation efficiency}

In addition to the selectivity of a chromatographic method for the particular compound of interest, the efficiency should also be taken into consideration. To evaluate the efficiency of an isothermal method, separation factor $(\alpha)$ values are taken into account and are calculated by,

$$
\alpha=t_{R(2)} / t_{R(1)}
$$

While, efficiency in a temperature programmed GC is usually evaluated by the separation number, $\mathrm{SN}$, which is the number of peaks that can be resolved between two members of a homologous series i.e two fatty acids differ by one methylene group (for example $\mathrm{C}_{14: 0}, \mathrm{C}_{16: 0,}, \mathrm{C}_{18: 0}$ or $\mathrm{C}_{14: 1}, \mathrm{C}_{16: 1}, \mathrm{C}_{18: 1}$ ). $\mathrm{SN}$ is usually calculated by,

$$
S N=\left(t_{R(z+1)}-t_{R(z)} / w_{h(z+1)}+w_{h(z)}\right)-1
$$

Where, $t_{R(z+1)}$ and $t_{R(z)}$ are the retention times of the two homologous fatty acids and $\mathrm{w}_{\mathrm{h}(\mathrm{z}+1)}$ and $\mathrm{w}_{\mathrm{h}(\mathrm{z})}$ are the corresponding peak widths at half peak height (Ettre, 1993).

\subsubsection{Ag-TLC method}

Ag-TLC fractionation of FAME was performed to separate the trans fraction from the cis fraction. Preparative Ag-TLC plates were prepared by incorporating $10 \%$ silver nitrate into the silica slurry in distilled water and applied onto glass plates and activated by drying at $100{ }^{\circ} \mathrm{C}$ for 1 hour (Morris, 1966). The FAME of PHF, butter, vaccenic and elaidic acid were spotted onto Ag-TLC plates and developed using hexane and diethyl ether in the ratio 80:20. Saturated, cis and trans fractions were located under U.V light and scrapped out from the prepared TLC plate, further re-extracted using hexane and further injected into GC.

\section{RESULTS AND DISCUSSION}

\subsection{Effect of column temperature on resolution}

In the isothermal program, the $\mathrm{C}_{4: 0}, \mathrm{C}_{6: 0}, \mathrm{C}_{8: 0}$ fatty acid peaks were eluted along with the solvent peak at the early retention time (Figure 1a). We have also observed less resolution between cis/ trans fatty acids with partial overlapping in the isothermal program. But, in the time-temperature program, there was a distinct separation among all fatty acids including short chain fatty acids. High initial temperatures in the GC program causes overlapping of the solvent front and short chain fatty acid peaks. This fact is the main cause of error in fat analysis (Kramer et al., 2008). In the isothermal program, resolution between cis/trans fatty acids was $<1.0$ (Figure 1b) while, in time-temperature program improved separation was observed. Resolution between cis/trans isomers of $\mathrm{C}_{14: 1}$ fatty acid was 2.9 and between cis/trans isomers of $\mathrm{C}_{16: 1}$ fatty acid was 1.8. Resolution between cis/ trans isomers of $\mathrm{C}_{18: 1}$ is an important factor in $\mathrm{GC}$ analysis. It was 2.3 between $C_{18: 1} 9 t$ and $C_{18: 1} 9 \mathrm{c}$ (Figure 2a), while it was 1.8 between $\mathrm{C}_{18: 1} 11 \mathrm{t}$ and $\mathrm{C}_{18: 1} 9 \mathrm{c}$ (Figure 2b). But the resolution between a mixture of trans isomers i.e. between $\mathrm{C}_{18: 1}$ 9t and $\mathrm{C}_{18: 1} 11 \mathrm{t}$ was 0.9 in the time-temperature program and no resolution was observed in the isothermal method. It has been found that a decrease in the operating temperature $\left(180^{\circ} \mathrm{C}\right)$ allows for better separation of the trans isomers of $\mathrm{C}_{18: 1}$ fatty acid (Ratnayake et al., 2002). These results suggest that the time-temperature program is preferable to an isothermal program to separate cis/trans isomers of oleic acid, which is predominant in PHF. Resolution between $\mathrm{C}_{18: 2}$ tt and $c t$ isomers was 3.6 and between $c t$ and $t c$ isomers it was 1.5. The resolution obtained between the $\mathrm{C}_{18: 3}$ isomers was $>1$. It was 3.9 between $t t t$ and $t t c$ isomers and 3.1 between $c t t$ and ctc isomers. The resolution between tct and ctt isomers was 1.2. ttc and tct and ctc and tct isomers were completely co-eluted (Figure 2c). These results clearly indicate the higher efficiency of the cyanopropyl column to separate fatty acid mixtures in the time-temperature program.

The geometrical isomers of conjugated linoleic acids (CLA), which are major compositions of

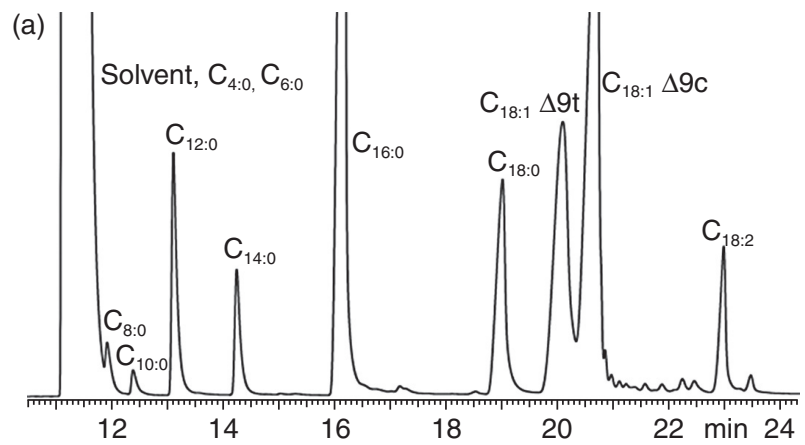

(b)

$$
\underline{\mathrm{C}_{18: 2} \text { isomers }}
$$

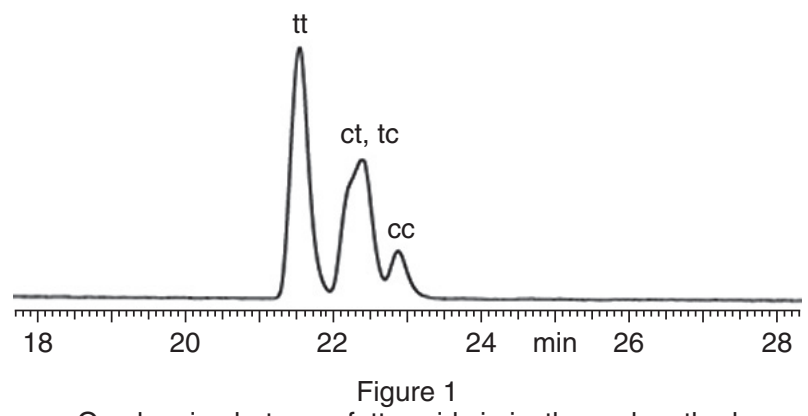

Overlapping between fatty acids in isothermal method (a) GC fatty acid profile of the puff sample (b) Separation of cis/trans isomers of linoleic acid methyl ester standard 
ruminant derived foods, are difficult to separate by the same method. So, there is a need to follow a different method for the separation of CLA isomers, especially in the analysis of milk and meat products (Kramer et al., 2008). tt, ct and tc forms of CLA $\left(\mathrm{C}_{18: 2} \Delta 8 \Delta 10, \mathrm{C}_{18: 2} \Delta 9 \Delta 11\right.$ and $\left.\mathrm{C}_{18: 2} \Delta 10 \Delta 12\right)$ are not included in the definition of trans fat given by the US FDA (U.S.FDA, 2003). So, CLA has no significance with respective to the labeling of trans fat contents. But, Negative effects of conjugated $t t$ isomers similar to non-conjugated $t t$ isomers are still making question marks regarding CLA and trans fat definitions.

\subsection{EFFECT OF CARRIER GAS AND LINEAR VELOCITY ON RESOLUTION}

Carrier gas is an important factor in chromatography i.e. the separation and the elution order can change when one carrier gas is substituted by another
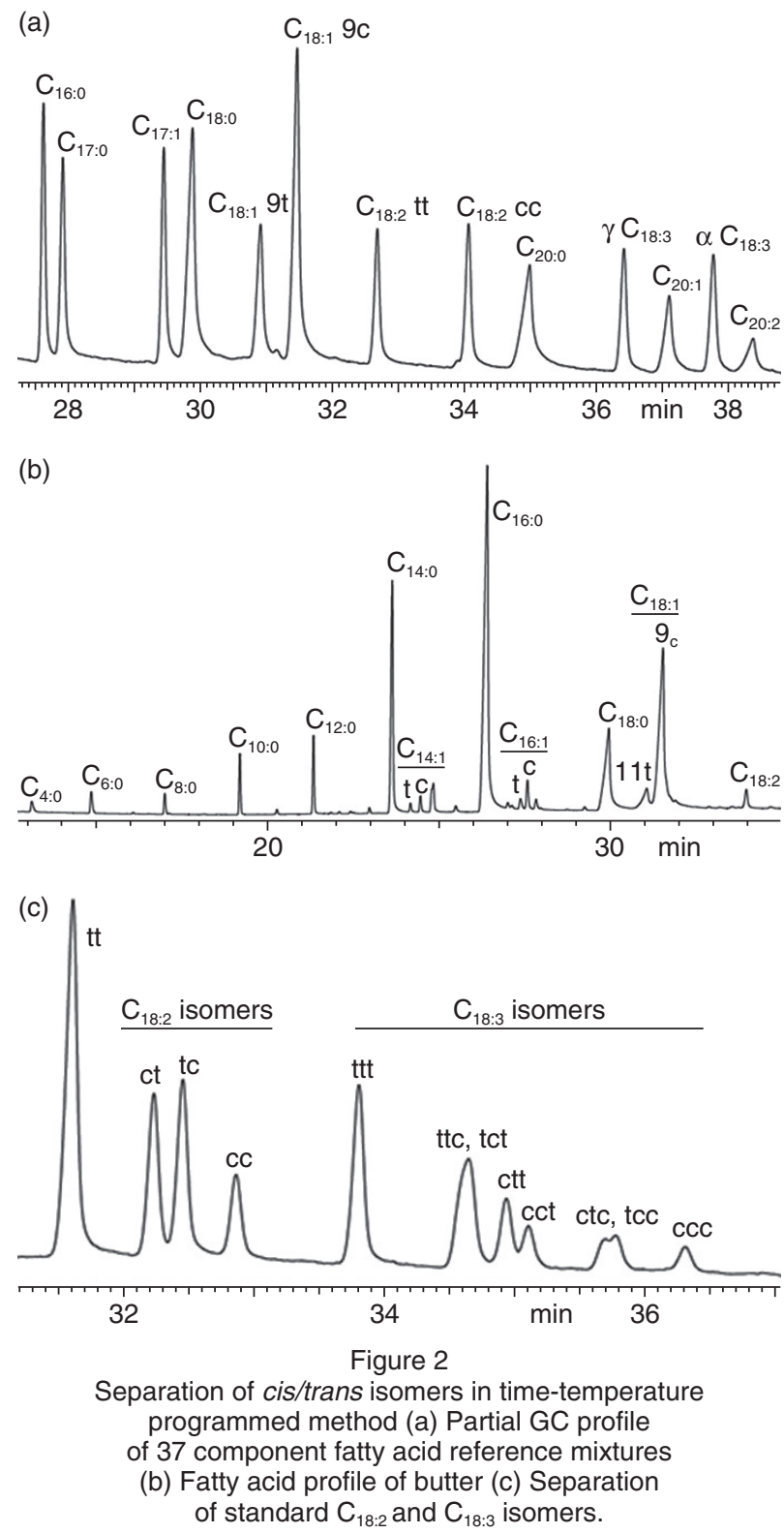

(Berezkin et al., 2003). At the same linear velocity of nitrogen and helium $\left(13.0 \mathrm{~cm} \mathrm{~s}^{-1}\right)$, resolution between cis/trans isomers of fatty acids was similar (Table 1). There was not much change in the resolution or the total run time when the linear velocity was increased. The linear velocity range is more restricted by the choice of length and inner diameter of the column relative to the inlet pressure that the instrument can provide. Linear velocity for GC column was optimized by the retention time of an unretained peak and its length (Ettre, 1993). In our study, we have observed that an increase in linear velocity affects the resolution between cis/trans isomers of fatty acids. Maintaining the medium linear velocities gives good resolution between fatty acids and total run time. Changing from helium to nitrogen and maintaining the same linear velocity would not change the elution pattern. Hydrogen can be used as a carrier gas and it provides very good resolution with a very short run time of analysis. Using hydrogen as a carrier gas is included with risk of explosions, through an electric spark igniting a buildup of gas caused by a leak within the instrument (Christe, 1989). So, nitrogen can be used as carrier gas instead of helium, because it is widely available, inexpensive and recommended for safety purposes.

\subsection{LOD AND LOQ}

LOD and LOQ in any analysis provide the detection limit and quantification limits of compounds of interest. In this study, the estimated LOD and LOQ for individual TFA components were $0.002 \mathrm{mg} \mathrm{mL}^{-1}$ and $0.006 \mathrm{mg} \mathrm{mL}^{-1}$ respectively. Lower detection limits and quantification limits indicate higher instrumental sensitivity.

\subsection{SEPARATION EFFICIENCY}

The separation factor for the all fatty acids was > 1 in isothermal conditions. In the time-temperature programmed method, the greater the separation number, the greater the separation will be of compounds in the column. Programmed methods with $\mathrm{SN}<10$ will show poor performance in GC analysis. In the time-temperature programmed method SN between myristic acid methyl ester and palmitic acid methyl ester was 15 , between palmitic acid methyl ester and stearic acid methyl ester it was 12. SN between myristoleic acid methyl ester and palmitoleic acid methyl ester was 18. While, it was 19 between palmitoleic acid methyl ester and oleic acid methyl ester, this was reasonably good separation efficiency.

\subsection{EFFECT OF AG-TLC FRACTIONATION}

TLC plate is generally used for confirmation of trans-esterification reaction completion (Figure $3 a$ ). TLC plates with silica gel $60 \mathrm{~F}_{254}$ produce yellowgreen emissions, upon irradiating with short wave UV 
Table 1

Resolution between major fatty acids with different carrier gasses

\begin{tabular}{|c|c|c|c|c|}
\hline \multirow{2}{*}{ Fatty acid } & \multicolumn{2}{|c|}{ Nitrogen as Carrier gas } & \multicolumn{2}{|c|}{ Helium as Carrier gas } \\
\hline & $t_{R}{ }^{a}$ & $\mathbf{R}_{\mathrm{s}}{ }^{\mathrm{b}}$ & $t_{R}{ }^{a}$ & $\mathbf{R}_{\mathrm{s}}{ }^{\mathbf{b}}$ \\
\hline $\mathrm{C}_{4: 0}$ & 13.1 & - & 12.0 & - \\
\hline$C_{6: 0}$ & 14.8 & 14.8 & 13.3 & 11.2 \\
\hline $\mathrm{C}_{8: 0}$ & 17.0 & 22.1 & 14.0 & 24.5 \\
\hline$C_{10: 0}$ & 19.2 & 26.4 & 16.0 & 12.9 \\
\hline$C_{12: 0}$ & 21.3 & 27.2 & 18.0 & 13.1 \\
\hline$C_{14: 0}$ & 23.6 & 24.3 & 19.9 & 21.7 \\
\hline $\mathrm{C}_{14: 1} \Delta 9 \mathrm{t}$ & 23.8 & 8.3 & 20.8 & 9.6 \\
\hline $\mathrm{C}_{14: 1} \Delta 9 \mathrm{C}$ & 24.2 & 2.9 & 20.9 & 1.0 \\
\hline$C_{16: 0}$ & 26.4 & 8.6 & 22.1 & 9.5 \\
\hline $\mathrm{C}_{16: 1} \Delta 9 \mathrm{t}$ & 27.3 & 5.8 & 22.9 & 5.3 \\
\hline $\mathrm{C}_{16: 1} \Delta 9 \mathrm{c}$ & 27.5 & 1.8 & 23.0 & 1.6 \\
\hline$C_{18: 0}$ & 29.9 & 3.8 & 24.9 & 3.5 \\
\hline $\mathrm{C}_{18: 1} \Delta 9 \mathrm{t}$ & 30.9 & 4.7 (PHF) & 25.5 & 4.7 (PHF) \\
\hline $\mathrm{C}_{18: 1} \Delta 11 \mathrm{t}$ & 31.0 & 4.2 (Butter) & 25.7 & 3.4 (Butter) \\
\hline $\mathrm{C}_{18: 1} \Delta 9 \mathrm{c}$ & 31.5 & $\begin{array}{l}2.3(\Delta 9 t) \\
1.8(\Delta 11 t)\end{array}$ & 26.0 & $\begin{array}{l}2.2(\Delta 9 t) \\
1.6(\Delta 11 t)\end{array}$ \\
\hline $\mathrm{C}_{18: 2} \Delta 9 \mathrm{t} \Delta 12 \mathrm{t}$ & 33.1 & 3.4 & 26.8 & 3.6 \\
\hline $\mathrm{C}_{18: 2} \Delta 9 \mathrm{c} \Delta 12 \mathrm{t}$ & 33.6 & 3.6 & 27.3 & 3.6 \\
\hline $\mathrm{C}_{18: 2} \Delta 9 \mathrm{t} \Delta 12 \mathrm{c}$ & 33.9 & 1.5 & 27.5 & 1.5 \\
\hline $\mathrm{C}_{18: 2} \Delta 9 \mathrm{c} \Delta 12 \mathrm{c}$ & 34.3 & 2.6 & 27.8 & 2.6 \\
\hline $\mathrm{C}_{18: 3} \Delta 9 \mathrm{t} \Delta 12 \mathrm{t} \Delta 15 \mathrm{t}$ & 35.0 & 5.3 & 28.5 & 5.4 \\
\hline $\mathrm{C}_{18: 3} \Delta 9 \mathrm{t} \Delta 12 \mathrm{t} \Delta 15 \mathrm{c}$ & 35.9 & 3.9 & 29.1 & 4.3 \\
\hline $\mathrm{C}_{18: 3} \Delta 9 \mathrm{t} \Delta 12 \mathrm{c} \Delta 15 \mathrm{t}$ & 36.2 & - & 29.4 & - \\
\hline $\mathrm{C}_{18: 3} \Delta 9 \mathrm{c} \Delta 12 \mathrm{t} \Delta 15 \mathrm{t}$ & 36.3 & 1.2 & 29.5 & 1.6 \\
\hline $\mathrm{C}_{18: 3} \Delta 9 \mathrm{c} \Delta 12 \mathrm{t} \Delta 15 \mathrm{c}$ & 36.9 & 3.1 & 30.0 & 1.2 \\
\hline $\mathrm{C}_{18: 3} \Delta 9 \mathrm{t} \Delta 12 \mathrm{c} \Delta 15 \mathrm{c}$ & 37.3 & - & 30.2 & - \\
\hline $\mathrm{C}_{18: 3} \Delta 9 \mathrm{c} \Delta 12 \mathrm{c} \Delta 15 \mathrm{c}$ & 37.6 & 2.3 & 30.4 & 3.0 \\
\hline
\end{tabular}

${ }^{\mathrm{a}}$ Retention time; ${ }^{\mathrm{b}}$ Resolution

light $(\lambda=254 \mathrm{~nm})$. It is due to an additive, a so-called "fluorescence indicator", e.g. manganese-activated zinc silicate, that is usually mixed with the sorbent (Elke Hahn-Deinstrop, 2006). Usually, Fatty acids do not separate on a normal TLC plate (Figure 3a). But, on an Ag-TLC plate, cis fatty acids form a complex with silver ions on TLC, more strongly than trans fatty acids. It is due to the steric hindrance of the trans bond. It causes the trans fraction to separate from the cis fraction, which elutes on the Ag-TLC plate. Due to the lack of double bonds, mobility of saturated fatty acids is higher, which elutes near the solvent front. The order of separation of fatty acids is cis, trans and saturated forms (Figure $3 \mathrm{~b}$ ). The Ag-TLC method was found to be a good alternative for TFA analysis in samples having interferences that cause inaccurate results in the analysis of some complex food matrices in cyanopropyl columns (Mjøs and Haugsgjerd,
2011). Common interferences for TFA analysis in a cyanopropyl column are presented in Table 2 . Results have been published based on the separation of linoleic and linolenic acid isomers through Ag-TLC (Elke Hahn-Deinstrop, 2006). But, the GC method could also successfully resolve cis/trans isomers and also trans/trans isomers of $\mathrm{C}_{18: 2}$ and $\mathrm{C}_{18: 3}$ fatty acids. But, the separation of the mixture of trans/trans isomers of oleic acid i.e. $\mathrm{C}_{18: 1} \Delta 9 \mathrm{t}$ and $\mathrm{C}_{18: 1} \Delta 11 \mathrm{t}$ by the Ag-TLC method is still limited. Figure 4 shows the co-elution of elaidic acid and vaccenic acid even after separation on an Ag-TLC plate. Plate lengths, activating time, the polarity of the solvent system are other critical parameters that affect the separation of cis/trans fatty acids on the Ag-TLC plate. Usually, impregnated plates are activated at $110{ }^{\circ} \mathrm{C}$ for $30 \mathrm{~min}$ for thin layers or for $60 \mathrm{~min}$ for thicker layers $(1 \mathrm{~mm})$. One serious difficulty in preparing plates is 
(a)

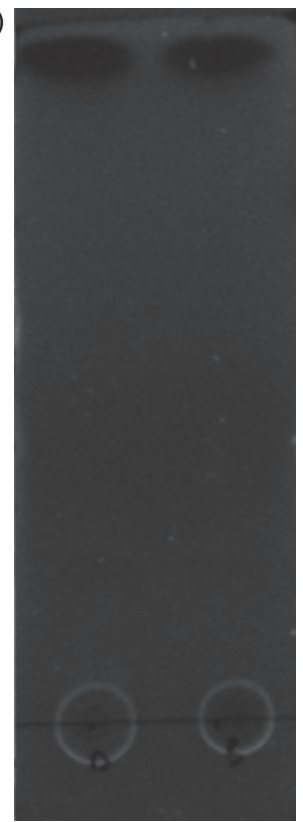

(b)

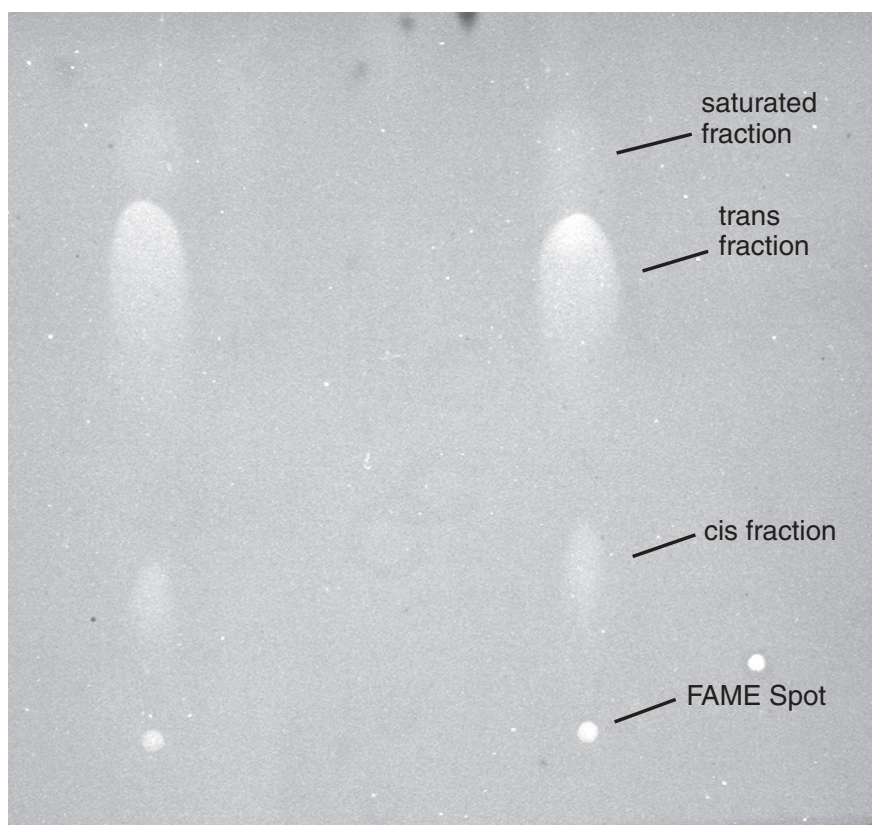

Figure 3

(a) Separation of PHF and butter FAME on pre-coated TLC plate

(b) Separation of PHF and butter FAME on Preparative Ag-TLC plate.

caused by the interaction of the silver nitrate solution with the metal of conventional plate spreaders. This interaction has two effects; metallic silver is precipitated onto the layers being prepared and the spreader itself becomes rapidly pitted and corroded until, eventually, it is useless (Morris, 1966). An Ag-HPLC method for the separation of cis/trans isomers has been reported (Momchilova et al., 1998).

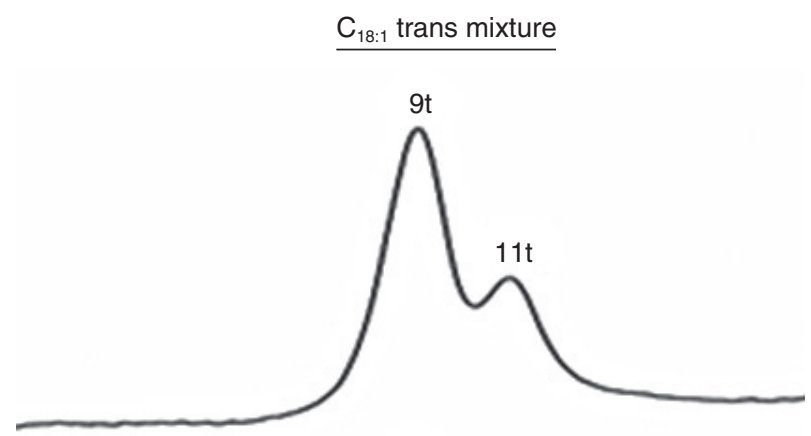

$9 t$

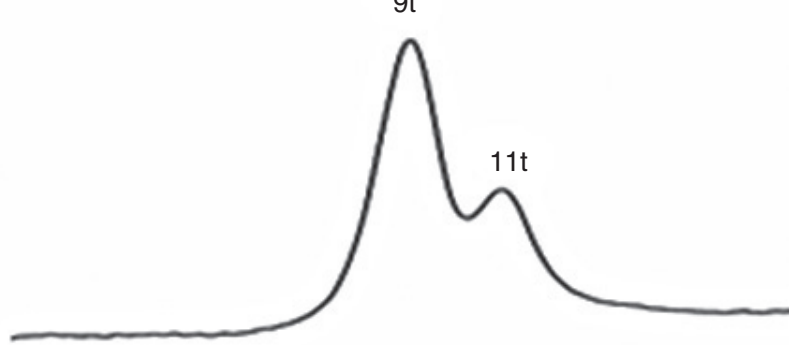

31

$\min$

Figure 4

Separation of mixture of elaidic acid and vaccenic acid on GC, before and after Ag-TLC fractionation.
Fractionation by liquid chromatography prior to GC analysis can eliminate the co-elution of fatty acids belonging to different classes, but incorrect practices might lead to greater measurement errors than those caused by the co-elution that affect the direct GC analysis (Aro et al., 1998). So, the GC method can be followed instead of Ag-TLC coupled with the GC method for the analysis of a large number of samples. But, in practice, it is difficult to separate all uncommon geometrical isomers of fatty acids in a GC column, which can be prepared chemically by p-toluene sulfonic acid isomerization or single step bromination and de-bromination. Recently, it has been found that SLB-IL-111, a highly polar ionic liquid coated capillary column can be used to separate cis/ trans and trans/trans isomers of conjugated and nonconjugated fatty acids with less overlapping among fatty acids by simple GC analysis (Ragonese et al., 2009; Delmonte et al., 2011).

\section{CONCLUSIONS}

In this study, the separation of cis/trans isomers of fatty acids was performed in a $75 \mathrm{~m}$ SP2560 column. Improved separation of cis/trans isomers of the $\mathrm{C}_{14: 1}, \mathrm{C}_{16: 1}, \mathrm{C}_{18: 1}, \mathrm{C}_{18: 2}, \mathrm{C}_{18: 3}$ fatty acids and short chain fatty acids was observed in the timetemperature program compared to the isothermal program. The separation of a mixture of trans isomers of oleic acid i.e. $\mathrm{C}_{18: 1} \Delta 9 \mathrm{t}$ and $\mathrm{C}_{18: 1} \Delta 11 \mathrm{t}$ with high resolution through simple $\mathrm{GC}$ technique is quite challenging. Ag-TLC fractionation prior to applying the GC method was proven to be a better option to analyze cis/trans isomers of fatty acids accurately. But, the separation of a mixture of trans isomers by further GC analysis is limited 
Table 2

Possible interferences in the TFA analysis in cyanopropyl columns

\begin{tabular}{|c|c|}
\hline Trans fatty acid & Possible interference \\
\hline $\mathrm{C}_{14: 1} \Delta 9 \mathrm{t}$ (Myristelaidic acid) & - \\
\hline $\mathrm{C}_{16: 1} \Delta 9 \mathrm{t}$ (Palmitelaidc acid) & $\begin{array}{l}\text { a) cis } 16: 1 \mathrm{n} 9 \\
\text { b) cis } 16: 1 \mathrm{n} 11 \\
\text { c) Iso } 17: 0 \text { (15-methyl hexadecanoic } \\
\text { acid) } \\
\text { d) ante-iso } 17: 0 \text { (15-methyl } \\
\text { hexadecanoic acid) } \\
\text { e) Phytanic acid ( } 3,7,11,15 \text {-Tetramethyl } \\
\text { hexadecanoic acid) }\end{array}$ \\
\hline $\begin{array}{l}\mathrm{C}_{18: 1} \Delta 6 \mathrm{t} \text { (petroselaidic acid) } \\
\mathrm{C}_{18: 1} \Delta 9 \mathrm{t} \text { (elaidic acid) } \\
\mathrm{C}_{18: 1} \Delta 11 \mathrm{t} \text { (transvaccenic acid) }\end{array}$ & $\begin{array}{l}\text { a) cis } 16: 3 n 3 \\
\text { b) cis } 16: 3 n 3 \\
\text { c) cis } 16: 4 n 3 \\
\text { d) cis } 18: 1 \mathrm{n} 11\end{array}$ \\
\hline $\begin{array}{l}\mathrm{C}_{18: 2} \Delta 9 \mathrm{t} \Delta 12 \mathrm{t} \text { (Linoleic acid trans forms) } \\
\mathrm{C}_{18: 2} \Delta 9 \mathrm{c} \Delta 12 \mathrm{t} \\
\mathrm{C}_{18: 2} \Delta 9 \mathrm{t} \Delta 12 \mathrm{c}\end{array}$ & $\begin{array}{l}\text { a) cis } 16: 4 \mathrm{n} 1 \\
\text { b) cis } 16: 4 \mathrm{n} 3 \\
\text { c) } 19: 0\end{array}$ \\
\hline $\begin{array}{l}\mathrm{C}_{18: 2} \Delta 7 \mathrm{c} \Delta 9 \mathrm{c}, \Delta 9 \mathrm{c} \Delta 11 \mathrm{c} \& \Delta 10 \mathrm{c} \Delta 12 \mathrm{c} \text { trans forms (tt, } \\
\text { ct \& tc forms) i.e CLA } \\
\text { (Not included in the definition of trans fat by USFDA) }\end{array}$ & $21: 0$ \\
\hline $\begin{array}{l}\mathrm{C}_{18: 3} \Delta 9 \mathrm{t} \Delta 12 \mathrm{t} \Delta 15 \mathrm{t} \text { (Linolenic acid trans forms) } \\
\mathrm{C}_{18: 3} \Delta 9 \mathrm{t} \Delta 12 \mathrm{t} \Delta 15 \mathrm{t} \\
\mathrm{C}_{18: 3} \Delta 9 \mathrm{t} \Delta 12 \mathrm{t} \Delta 15 \mathrm{c} \\
\mathrm{C}_{18: 3} \Delta 9 \mathrm{t} \Delta 12 \mathrm{c} \Delta 15 \mathrm{t} \\
\mathrm{C}_{18: 3} \Delta 9 \mathrm{c} \Delta 12 \mathrm{t} \Delta 15 \mathrm{t} \\
\mathrm{C}_{18: 3} \Delta 9 \mathrm{c} \Delta 12 \mathrm{c} \Delta 15 \mathrm{t} \\
\mathrm{C}_{18: 3} \Delta 9 \mathrm{c} \Delta 12 \mathrm{t} \Delta 15 \mathrm{c} \\
\mathrm{C}_{18: 3} \Delta 9 \mathrm{t} \Delta 12 \mathrm{c} \Delta 15 \mathrm{c}\end{array}$ & $\begin{array}{l}\text { a) cis 18:3 n4 } \\
\text { b) cis 18:3 n6 } \\
\text { c) cis 20:0 } \\
\text { d) cis 20:1 n9 } \\
\text { e) cis 20:1 n11 }\end{array}$ \\
\hline $\mathrm{C}_{20: 1} \Delta 13 \mathrm{t}$ (Brassidic acid) & - \\
\hline $\mathrm{C}_{20: 5} \Delta 5 \Delta 8 \Delta 11 \Delta 14 \Delta 17$ (EPA) trans forms & $\begin{array}{l}\text { a) } 20: 4 n 3 \\
\text { b) } 22: 0 \\
\text { c) } 22: 1\end{array}$ \\
\hline $\mathrm{C}_{22: 6} \Delta 4 \Delta 7 \Delta 10 \Delta 13 \Delta 16 \Delta 19(\mathrm{DHA})$ trans forms & - \\
\hline
\end{tabular}

especially for $\mathrm{C}_{18: 1} \mathrm{FAME}$ isomers. Moreover, the Ag-TLC method is more expensive and time consuming. A highly polar cyanopropyl column can be used for the analysis of TFA with a simple GC technique for a large number of samples. This work also suggests that the chromatographers' need to optimize the methods for TFA analysis depends on the column length.

\section{ACKNOWLEDGEMENTS}

The authors are thankful to the Directorate of Vanaspati, Ministry of Food and Consumer Affairs, India, for their financial support to this study.

\section{REFERENCES}

AOCS. 2003. Official methods and recommended practices of the American Oil Chemist's Society. In Firestone (Ed.), 5th edition, Champaign. IL.
Aro A, Kosmeijer-Schuil T, Bovenkamp P, Hulshof $\mathrm{P}$, Zock P, Katan M. 1998. Analysis of C18:1 cis and trans fatty acid isomers by the combination of gasliquid chromatography of 4,4-dimethyloxazoline derivatives and methyl esters. J. Am. Oil Chem. Soc. 75, 977-985.

Berezkin VG, Zagainov VF, Ivanov PB. 2003. Carrier gas as a new factor influencing the selectivity of the gasstationary liquid phase chromatographic system. J. Chromatogr. A 985, 57-62.

Christe WW. 1989. Gas chromatography and lipids: a practical guide. Oily press limited. First edition.

Delmonte P, Rader J. 2007. Evaluation of gas chromatographic methods for the determination of trans fat. Anal. Biochem. 389, 77-85.

Delmonte P, Fardin Kia A-R, Kramer JKG, Mossoba MM, Sidisky L, Rader JI. 2011. Separation characteristics of fatty acid methyl esters using SLB-IL111, a new ionic liquid coated capillary gas chromatographic column. J. Chromatogr. A 1218, 545-554.

Elke Hahn-Deinstrop. 2006. Applied Thin Layer Chromatography. Best practice and Avoidance of Mistakes. WILEY-VCH Verlag GmbH \& Co. KGaA, Weinheim, Second Edition. 
Ettre LS. 1993. Nomenclature for chromatography. Pure Appl. Chem. 65, 819.

Folch J, Lees M, Stanley GHS. 1957. A simple method for the isolation and purification of total lipids from animal tissues. J. Biol. Chem. 226, 497-509.

Fournier V, Destaillats F, Hug B, Golay P-A, Joffre F, Juanéda $P$, Sémon $E$, Dionisi F, Lambelet $P$, Sébédio J-L, Berdeaux O. 2007. Quantification of eicosapentaenoic and docosahexaenoic acid geometrical isomers formed during fish oil deodorization by gas-liquid chromatography. J. Chromatogr. A 1154, 353-359.

Huang Z, Wang B, Crenshaw AA. 2006. A simple method for the analysis of trans fatty acid with GC-MS and ATTM Silar-90 capillary column. Food Chem. 98, 593-598.

IUPAC. 1987. Standard methods for the analysis of oils and fats and derivatives. 7th Ed., London: Blackwell Scientific Publications.

Juanéda $P$, Ledoux M, Sébédio JL. 2007. Analytical methods for determination of trans fatty acid content in food. Eur. J. Lipid Sci. Technol. 109, 901-917.

Kramer J, Hernandez M, Cruz-Hernandez C, Kraft J, Dugan M. 2008. Combining Results of Two GC Separations Partly Achieves Determination of All cis and trans 16:1, 18:1, 18:2 and 18:3 Except CLA Isomers of Milk Fat as Demonstrated Using Ag-Ion SPE Fractionation, Lipids 43, 259-273.

Ledoux M, Laloux L, Wolff RL. 2000. Analytical methods for determination of trans-C18 fatty acid isomers in milk fat. A review. Analysis 28, 402.

Micha R, Mozaffarian 2008. Trans fatty acids: effects on cardiometabolic health and implications for policy. Prostag. Leukotr. Ess. 79, 147-152.

Morris LJ. 1966. Separations of lipids by silver ion chromatography. J. Lipid. Res. 7 (6):717-732

Mjøs SA. 2005. Properties of trans isomers of eicosapentaenoic acid and docosahexaenoic acid methyl esters on cyanopropyl stationary phases. J. Chromatogr. A 1100, 185-192.

Mjøs SA, Haugsgjerd BO. 2011. Trans Fatty Acid Analyses in Samples of Marine Origin: The Risk of False Positives. J. Agric. Food Chem. 59, 3520-3531.

Molkentin J, Precht D. 1995. Optimized analysis transoctadecenoic acids in edible fats. Chromatographia 41, 267-272.

Momchilova S, Nikolova-Damyanova B, Christie WW. 1998. Silver ion high-performance liquid chromatography of isomeric cis- and trans-octadecenoic acids: Effect of the ester moiety and mobile phase composition. $J$. Chromatogr. A 793, 275-282.

Mozaffarian D, Katan MB, Ascherio A, Stampfer MJ, Willett WC. 2006. Trans Fatty Acids and Cardiovascular Disease. New Engl. J. Med. 354, 1601-1613.
Phillips K, Ruggio D, Amanna K. 2010. Optimization of Standard Gas Chromatographic Methodology for the Determination of Trans Fat in Unlabeled Bakery Products. J. Food Anal. Methods 3, 277-294

Ragonese C, Tranchida PQ, Dugo P, Dugo G, Sidisky LM, Robillard MV, Mondello L. 2009. Evaluation of Use of a Dicationic Liquid Stationary Phase in the Fast and Conventional Gas Chromatographic Analysis of Health-Hazardous C18 Cis/Trans Fatty Acids. Anal. Chem. 81, 5561-5568.

Ratnayake WMN, Beare-Rogers JL. 1990. Problems of Analyzing C18 Cis- and Trans-Fatty Acids of Margarine on the SP-2340 Capillary Column. J. Chromatogr. Sci. 28, 633-639.

Ratnayake WMN, Plouffe JL, Pasquier E, Gagnon C. 2002. Temperature-sensitive resolution of cis- and trans-fatty acid isomers of partially hydrogenated vegetable oils on SP-2560 and CP-Sil 88 capillary columns. J. Am. Oil Chem. Soc. 85, 1112-1118.

Ratnayake WMN, Hansen LS, Kennedy PM. 2006. Evaluation of the CP-Sil 88 and SP-2560 GC Columns Used in the Recently Approved AOCS Official Method Ce 1h-05: Determination of cis-, trans- , Saturated, Monounsaturated and Polyunsaturated Fatty Acids in Vegetable or Non-ruminant Animal Oils and Fats by Capillary GLC Method. J. Am. Oil Chem. Soc. 83, 475-488.

Ruiz-Jiménez J, Priego-Capote F, de Castro MD. 2004. Identification and quantification of trans fatty acids in bakery products by gas chromatography-mass spectrometry after dynamic ultrasound-assisted extraction. J. Chromatogr. A 1045, 203-210.

Tasan M, Gecgel U, Demirci M. 2011. Comparison of geometrical isomerization of unsaturated fatty acids in selected commercially refined oils. Grasas Aceites 62, 284-289.

Tsuzuki W, Matsuoka A, Ushida K. 2010. Formation of trans fatty acids in edible oils during the frying and heating process. Food Chem. 123, 976-982.

U.S. Food and Drug Administration 2003. Food labeling: trans fatty acids in nutrition labeling, nutrient content claims, and health claims. 68 Federal Register 4143341506 (codified at21 CFR §101).

Valenzuela A, King J, Nieto S. 1995. Trans fatty acid isomers from hydrogenated fats: The controversy about health implications. Grasas Aceites 46, 357365.

Valenzuela A, Delplanque B, Tavella M. 2011. Stearic acid: a possible substitute for trans fatty acids from industrial origin. Grasas Aceites 62, 131-138.

Recibido: $31 / 7 / 12$ Aceptado: 5/12/12 